
LIVERMORE N A TION AL LABORATORY

\title{
Ignition and Growth Modeling of LX-17 Hockey Puck Experiments
}

Craig M. Tarver

May 10, 2004

Propellants, Explosives, Pyrotechnics 
This document was prepared as an account of work sponsored by an agency of the United States Government. Neither the United States Government nor the University of California nor any of their employees, makes any warranty, express or implied, or assumes any legal liability or responsibility for the accuracy, completeness, or usefulness of any information, apparatus, product, or process disclosed, or represents that its use would not infringe privately owned rights. Reference herein to any specific commercial product, process, or service by trade name, trademark, manufacturer, or otherwise, does not necessarily constitute or imply its endorsement, recommendation, or favoring by the United States Government or the University of California. The views and opinions of authors expressed herein do not necessarily state or reflect those of the United States Government or the University of California, and shall not be used for advertising or product endorsement purposes. 


\title{
IGNITION AND GROWTH MODELING OF LX-17 HOCKEY PUCK EXPERIMENTS
}

\author{
Craig M. Tarver \\ Energetic Materials Center \\ Lawrence Livermore National Laboratory \\ Livermore, CA 94550 (USA)
}

\begin{abstract}
$\underline{\text { ABSTRACT }}$
Detonating solid plastic bonded explosives (PBX) formulated with the insensitive molecule triaminotrinitrobenzene (TATB) exhibit measurable reaction zone lengths, curved shock fronts, and regions of failing chemical reaction at abrupt changes in the charge geometry. A recent set of "hockey puck" experiments measured the breakout times of diverging detonation waves in ambient temperature LX-17 (92.5\% TATB plus 7.5\% Kel-F binder) and the breakout times at the lower surfaces of $15 \mathrm{~mm}$ thick LX-17 discs placed below the detonatorbooster plane. The LX-17 detonation waves in these discs grow outward from the initial wave leaving regions of unreacted or partially reacted TATB in the corners of these charges. This new experimental data is accurately simulated for the first time using the Ignition and Growth reactive flow model for LX-17, which is normalized to a great deal of detonation reaction zone, failure diameter and diverging detonation data. A pressure cubed dependence for the main growth of reaction rate yields excellent agreement with experiment, while a pressure squared rate diverges too quickly and a pressure quadrupled rate diverges too slowly in the LX-17 below the booster equatorial plane.
\end{abstract}




\section{INTRODUCTION}

It has long been known that self-sustaining detonation waves in solid plastic bonded explosives (PBX) formulated with the insensitive high explosive molecule triaminotrinitrobenzene (TATB) exhibit regions of zero or partial chemical reaction in spherical divergent or corner turning experiments [1]. Recently proton radiography [2] and Fabry-Perot laser interferometry [3] have applied to diverging detonations in PBX 9502 (95\% TATB and 5\% Kel-F binder) and LX-17 (92.5\% TATB plus $7.5 \%$ Kel-F), respectively, to quantify the amount of unreacted explosive left at a corner and to measure the buildup of the detonation wave as it approaches its steady state Chapman-Jouguet (C-J) velocity and pressure. Since not all detonation reactive flows can be measured experimentally, hydrodynamic computer code models based on the Zeldovich - von Neumann - Doring (ZND)[4-6] and curved detonation front theories [7] have been developed to describe the unreacted shock front state, usually called the von Neumann spike, the reaction rates behind the shock front, the C-J state attained after reaction is complete, and the subsequent expansion of the reaction products. The Ignition and Growth reactive flow model $[3,8$ 27] has long been used to predict detonation wave propagation and metal acceleration in several one-, two- and three-dimensional hydrodynamic computer codes.

Recently a new experiment was developed by Roeske [28] to measure not only divergence of LX-17 detonation waves from a hemispherical booster but the growth of the wave into an adjoining section of LX-17 located below the detonator-booster plane. These charges are called "hockey pucks" due to their size and cylindrical shape. This paper compares two-dimensional Ignition and Growth reactive flow modeling of the LX-17 ambient temperature detonation wave breakout times with those measured in two different sized hockey puck experiments. Three reaction rate laws were used to illustrate the sensitivity of the calculated breakout timing.

\section{LX-17 HOCKEY PUCK EXPERIMENTAL GEOMETRIES}

The LX-17 hockey puck experiment with the $25.4 \mathrm{~mm}$ wide aft section is shown in Fig. 1. The LX-17 main charge consisted of a cylindrical sample with a cylindrical cutout on axis terminated in a hemispherical cutout to accept the booster and detonator. This LX-17 cylinder was $55.4 \mathrm{~mm}$ long with a $15 \mathrm{~mm}$ long cylindrical cutout. Two diameters of LX-17 were used: a $88.8 \mathrm{~mm}$ diameter in which the section aft of the booster was $25.4 \mathrm{~mm}$ wide and a $63.4 \mathrm{~mm}$ diameter in which the aft section width was $12.7 \mathrm{~mm}$. The boosters were $19.05 \mathrm{~mm}$ radius hemispheres of Ultrafine TATB with hemispherical cutouts to accept hemispherical detonators. The streak camera diagnostic measured the breakout times of the LX-17 detonation waves on the back surfaces behind the 
detonator/boosters and along the outer edges of the LX-17 cylinders. The distance coordinates shown in Fig. 1 are used throughout this paper. The distances along the back LX-17 surface vary from either $-12.7 \mathrm{~mm}$ or $-25.4 \mathrm{~mm}$ to zero $\mathrm{mm}$ and then are positive along the outer LX-17 surfaces, so that $15 \mathrm{~mm}$ represents the Ultrafine TATB equatorial position. Optical pins were placed at the outer edges of the Ultrafine TATB boosters to give initial times for the onset of the LX-17 detonations at the corners of the boosters. Crystal pins were placed directly in line with the initiation points and measured steady state C-J detonation velocities in LX-17 along the charge axes. Three Xray heads were fired at different time to obtain snapshots of the "dead zones" produced in the LX-17 samples just beyond the boosters [29]. The experimental streak camera breakout times for the $12.7 \mathrm{~mm}$ and $25.4 \mathrm{~mm}$ aft sections are shown in Fig. 2. The diverging LX-17 detonation waves above $15 \mathrm{~mm}$ in Fig. 2 slowly accelerate from 7.48 $\mathrm{mm} / \mu \mathrm{s}$ to $7.68 \mathrm{~mm} / \mu \mathrm{s}$, the Ultrafine TATB and LX-17 C-J detonation velocities, respectively. The arrival times from 0 to $15 \mathrm{~mm}$ measure the growth rate of these diverging detonation waves into the aft sections. The arrival times at the rear boundaries of the LX-17 from $-12.7 \mathrm{~mm}$ to $0 \mathrm{~mm}$ and from $-25.4 \mathrm{~mm}$ to $0 \mathrm{~mm}$ in Fig. $2 \mathrm{describe}$ the growth of the LX-17 waves around the unreacted or partially reacted regions formed at the Ultrafine TATB booster LX-17 boundaries. This new experimental data represents a unique challenge for the LX-17 Ignition and Growth reactive flow model, which is described in the next section.

\section{$\underline{\text { THE IGNITION AND GROWTH REACTIVE FLOW MODEL }}$}

All reactive flow models require as a minimum: two equations of state, one for the unreacted explosive and one for its reaction products; a reaction rate law for the conversion of explosive to products; and a mixture rule to calculate partially reacted states in which both explosive and products are present. The Ignition and Growth reactive flow model (14) uses two Jones-Wilkins-Lee (JWL) equations of state, one for the unreacted explosive and another one for the reaction products, in the temperature dependent form:

$$
p=A e^{-R_{1} V}+B e^{-R_{2} V}+\omega C_{V} T / V
$$

where $\mathrm{p}$ is pressure in Megabars, $\mathrm{V}$ is relative volume, $\mathrm{T}$ is temperature, $\omega$ is the Gruneisen coefficient, $\mathrm{C}_{\mathrm{V}}$ is the average heat capacity, and $\mathrm{A}, \mathrm{B}, \mathrm{R}_{1}$ and $\mathrm{R}_{2}$ are constants. The unreacted explosive equation of state is fitted to the available shock Hugoniot data, and the reaction product equation of state is fitted to cylinder test and other metal acceleration data. At the high pressures involved in shock initiation and detonation of solid and liquid explosives, the pressures of the two phases must be equilibrated, because interactions between the hot gases and the explosive 
molecules occur on nanosecond time scales depending on the sound velocities of the components. Various assumptions have been made about the temperatures in the explosive mixture, because heat transfer from the hot products to the cooler explosive is slower than the pressure equilibration process. In this version of the Ignition and Growth model, the temperatures of the unreacted explosive and its reaction products are equilibrated. Temperature equilibration is used, because heat transfer becomes increasingly efficient as the reacting "hot spots" grow and consume more explosive particles at the high pressures and temperatures associated with detonation. Fine enough zoning must be used in all reactive flow calculations so that the results have converged to an answer that does not change with finer zoning. Generally this requires a resolution of at least 10 zones for the detonation reaction zone. LX-17 has an experimentally measured reaction zone length of approximately three mm [23] so using 10 zones per mm spreads the reaction over 30 zones. For these and previous two-dimensional LX-17 Ignition and Growth detonation calculations, there are small differences between calculations using 5 zones per mm and those using 10 zones per mm and no observable differences between calculations using 10 zones per mm and those using 20 zones per mm. The DYNA2D [30] calculations reported herein used 10 zones per $\mathrm{mm}$ for both hockey puck dimensions.

The Ignition and Growth reaction rate equation is given by:

$$
\begin{aligned}
& d F / d t=I(1-F)^{b}\left(\rho / \rho_{o}-1-a\right)^{X}+G_{1}(1-F)^{c} F^{d} p^{y}+G_{2}(1-F)^{e_{F}} g_{p}^{Z} \\
& 0<\mathrm{F}<\mathrm{F}_{\text {igmax }} \quad 0<\mathrm{F}<\mathrm{F}_{\mathrm{G} 1 \text { max }} \quad \mathrm{F}_{\mathrm{G} 2 \min }<\mathrm{F}<1
\end{aligned}
$$

where $\mathrm{F}$ is the fraction reacted, $\mathrm{t}$ is time in $\mu \mathrm{s}, \rho$ is the current density in $\mathrm{g} / \mathrm{cm}^{3}, \rho_{\mathrm{o}}$ is the initial density, $\mathrm{p}$ is pressure in Mbars, and $\mathrm{I}_{1} \mathrm{G}_{1}, \mathrm{G}_{2}, \mathrm{a}, \mathrm{b}, \mathrm{c}, \mathrm{d}, \mathrm{e}, \mathrm{g}, \mathrm{x}, \mathrm{y}, \mathrm{z}, \mathrm{F}_{\mathrm{igmax}}, \mathrm{F}_{\mathrm{G} 1 \mathrm{max}}$, and $\mathrm{F}_{\mathrm{G} 2 \min }$ are constants. This three-term reaction rate law represents the three stages of reaction generally observed during shock initiation and detonation of pressed solid explosives (17). The first stage of reaction is the formation and ignition of "hot spots" caused by the various possible mechanisms discussed for impact ignition as the initial shock or compression wave interacts with the unreacted explosive molecules. Generally the fraction of solid explosive heated during shock compression is approximately equal to the original void volume. For shock initiation modeling, the second term in Eq. (2) then describes the relatively slow process of the inward and/or outward growth of the isolated "hot spots" in a deflagration-type process. The third term represents the rapid completion of reaction as the "hot spots" coalesce at high pressures and temperatures, resulting in transition from shock induced reaction to detonation.

For detonation modeling, the first term again reacts a quantity of explosive less than or equal to the void volume after the explosive is compressed to the unreacted von Neumann spike state. The second term in Eq. (2) 
models the fast decomposition of the solid into stable reaction product gases $\left(\mathrm{CO}_{2}, \mathrm{H}_{2} \mathrm{O}, \mathrm{N}_{2}\right.$, CO, etc.). The third term describes the relatively slow diffusion limited formation of solid carbon (amorphous, diamond, or graphite) as chemical and thermodynamic equilibrium at the C-J state is approached. These reaction zone stages have been observed experimentally using embedded gauges and laser interferometry.

The Ignition and Growth reactive flow model has been applied to a great deal of experimental shock initiation and detonation data using several one-, two-, and three-dimensional hydrodynamic codes. In shock initiation applications, it has successfully calculated many embedded gauge, run distance to detonation, short pulse duration, multiple shock, reflected shock, ramp wave compression, and divergent flow experiments on several high explosives at various initial temperatures (heating plus shock scenarios), densities, and degrees of damage (impact plus shock scenarios). For detonation wave applications, the model has successfully calculated embedded gauge, laser interferometric metal acceleration, failure diameter, corner turning, converging, diverging, and overdriven experiments [3,8-27].

The Ignition and Growth Ultrafine TATB and LX-17 model parameters used in these calculations are listed in Table 1. They were previously applied to Fabry-Perot laser interferometric Ultrafine TATB booster divergence experiments and several LX-17 detonation experiments, including "snowball" divergence and failure diameter. Since the detonation waves in the Ultrafine TATB boosters are curved and exhibit delays at the corner, reactive flow modeling of the booster is essential. The Ultrafine TATB was ignited by point lighting C-J detonation in a $6.65 \mathrm{~mm}$ radius hemisphere of PBX 9407 whose reaction product JWL equation of state is listed in Table 1. Zero time for the calculations is assumed to be the time of emergence of the Ultrafine TATB booster detonation wave into the LX-17 at its equator. This corresponds to the breakout times measured by the optical pins shown in Fig. 1. The calculated breakout times for detonating LX-17 for both hockey puck widths are compared to experiment in the next section.

\section{COMPARISION OF EXPERIMENTAL AND CALCULATED BREAKOUT TIMES}

Comparisons between the experimental and calculated breakout times along the LX-17 sample perimeters are shown in Figs. 3 and 4 for the $12.7 \mathrm{~mm}$ wide and $25.4 \mathrm{~mm}$ samples, respectively. For both widths, the calculated breakout timing along the outer edge of the LX-17 cylinders from the Ultrafine booster equator (15 mm) to the top of the charge agrees well with experiment, because this model has already been shown to predict the breakout times and the pressures and particle velocities of building LX-17 detonation waves measured in Fabry-Perot experiments 
$[3,26]$. The good agreement between experiment and calculation for the 0 to $15 \mathrm{~mm}$ distances in Figs. 3 and 4 implies that the model reactions are correctly simulating the growth of the diverging main LX-17 wave into the aft sections below the booster equator. The main comparisons are along the aft boundaries of the LX-17 charges from $12.7 \mathrm{~mm}$ to $0 \mathrm{~mm}$ in Fig. 3 and $-25.4 \mathrm{~mm}$ to $0 \mathrm{~mm}$ in Fig. 4. In Fig. 3, the calculated breakout times at the edges ($12.7 \mathrm{~mm}$ and $0 \mathrm{~mm}$ ) agree well with experiment. The calculated minimum breakout time is about $3.81 \mu \mathrm{s}$ at $-4 \mathrm{~mm}$, while the experimental minimum breakout time of $3.71 \mu$ s occurs at $-3 \mathrm{~mm}$. Since there is some uncertainty in both the experimental and computational zero times, this agreement is considered very good. For the $25.4 \mathrm{~mm}$ wide sample in Fig. 4, the calculated minimum breakout time is $3.37 \mu \mathrm{s}$ at $-13 \mathrm{~mm}$ and the corresponding experimental time is $3.57 \mu \mathrm{s}$ at $-14 \mathrm{~mm}$. Thus the calculated minimum breakout time for the $12.7 \mathrm{~mm}$ wide sample is slightly greater than that measured experimentally, while the calculated minimum breakout time for the $25.4 \mathrm{~mm}$ wide sample is slightly less than that measured experimentally. Both calculated first breakouts occur within one mm of those measured experimentally. Therefore the Ignition and Growth LX-17 detonation reactive flow model reproduces the experimentally measured breakout times for both hockey puck dimensions. The calculated unreacted or partially reacted regions of LX-17 produced at the booster - aft sample interfaces are very similar to the denser regions shown on the X-rays taken during these experiments [29], as they have been for many years on Phermex Xrays [1] and proton radiographs [2]. Figures $5-7$ show the unreacted LX-17 region formed in the one inch wide hockey puck experiments at $5.5,6$, and $6.5 \mu$ s after initiation, respectively $(2.735,3.235$, and $3.735 \mu$ s after the booster detonation wave breaks out at the equator). The contours marked "a" represent complete reaction, while contours marked "b" represent $80 \%$ reaction in Figs. $5-7$. The slower final $20 \%$ reaction is generally believed to be due to solid carbon particle formation [31]. The dimensions are in centimeters in Figs. $5-7$ so the calculated LX-17 reaction zone is $2.5-3 \mathrm{~mm}$ wide in most of the reactive flow and wider in regions of irregularity.

The close agreement between the Ignition and Growth calculations and the experimental breakout times is not accidental. These calculations used a pressure cubed growth of reaction rate for the second term in Eq. 2. Other pressure dependencies for this reaction rate, even when normalized to failure diameter and diverging detonation data, do not yield good simulations of these hockey puck experiments. Figures 8 and 9 show the breakout times calculated with pressure squared rates with $G_{1}=1100$ and pressure quadrupled rates using $G_{1}=23000$ rates along with the experimental data and the pressure cubed results for the $12.7 \mathrm{~mm}$ wide and $25.4 \mathrm{~mm}$ wide samples, respectively. All three reaction rates predict the breakout times of the diverging LX-17 waves well in the $15 \mathrm{~mm}$ to $45 \mathrm{~mm}$ regions. 
However, the pressure squared rate turns the corner much too easily and breaks out too early in the $-12.7 \mathrm{~mm}$ to 15 mm region of Fig. 8 and the -25.4 to $15 \mathrm{~mm}$ region of Fig. 9 . Very little unreacted LX-17 is predicted at the booster - LX-17 corner. The pressure quadrupled rate diverges poorly in the aft LX-17 section and arrives late in the -12.7 to $0 \mathrm{~mm}$ region in Fig. 8 and the -25.4 to $0 \mathrm{~mm}$ region in Fig. 9 . In fact, the calculated arrival times of 4.3 to $4.9 \mu$ s in the -10 to $-25.4 \mathrm{~mm}$ region of Fig. 9 are due to an unreacted shock front decaying from about $10 \mathrm{GPa}$ to $5 \mathrm{GPa}$ as it runs ahead of the detonation wave that is attempting to turn back into that region. A region of unreacted LX-17 much larger than those observed in corner turning experiments on TATB-based PBX's is predicted by this reaction rate law. Therefore pressure cubed is the correct dependence for the Ignition and Growth reaction rate law for detonating LX-17. These hockey puck experiments provided the clearest experimental data yet obtained for differentiating between various reaction rate laws in hydrodynamic reactive flow models.

\section{CONCLUSIONS}

The recent LX-17 hockey puck experiments provided unique data on the corner turning ability of insensitive TATB-based high explosives for testing the reaction rate dependencies used in hydrodynamic reactive flow models. This data was accurately calculated by the Ignition and Growth model using a pressure cubed reaction rate law for the growth of reaction in the LX-17 detonation reaction zone. Reaction rates based on pressure squared and pressure quadrupled predicted too early and too late breakout times, respectively, on the back surface of 12.7 mm and $25.4 \mathrm{~mm}$ wide LX-17 samples. Thus the LX-17 Ignition and Growth model with a pressure cubed rate law appears to be well suited to model LX-17 detonation waves in any one-, twe , or three-dimensional geometry. These hockey puck experiments were fired at ambient temperature, and additional hockey puck experiments will be fired at cold $\left(-55^{\circ} \mathrm{C}\right)$ and at warm $\left(+75^{\circ} \mathrm{C}\right)$ temperatures. Ignition and Growth reaction rate parameters for cold and warm LX-17 have been developed based on failure diameter and diverging detonation tests [26], and testing these parameters against hockey puck experimental data is critical to assure their usefulness.

The phenomenological Ignition and Growth has proved its basic validity and applicability to shock initiation and detonation modeling for many years. However, it must be re-parameterized for each initial density and temperature. Additionally, its compression and pressure dependent reaction rates are only approximate, because all chemical reaction rates depend on the local temperature of the explosive molecules that are currently undergoing reaction in the hottest regions of the reactive flow. A Statistical Hot Spot reactive flow model [32] has been developed in the ALE3D hydrodynamic code that is based on Arrhenius temperature controlled reaction rates. This 
model has already reproduced shock desensitization experimental data that other reactive models can not. Statistical Hot Spot model parameters for detonating LX-17 will be developed when all the various initial temperature hockey puck experiments have been conducted.

\section{ACKNOWLEDGMENTS}

This work was performed under the auspices of the United States Department of Energy by the University of California, Lawrence Livermore National Laboratory under Contract No. W-7405-ENG-48. 


\section{REFERENCES}

[1] C. L. Mader, "Two Dimensional Homogeneous and Heterogeneous Detonation Wave Propagation", Sixth Symposium (International) on Detonation, Coronado, CA, 1976, p. 405.

[2] E. N. Ferm, C. L. Morris, J. P. Quintana, P. Pazuchanic, H. Stacy, J. D. Zumbro, G. Hogan, and N. King, "Proton Radiography Examination of Unburned Regions in PBX 9502 Corner Turning Experiments," Shock Compression of Condensed Matter - 2001, M. D. Furnish, N. N. Thadhani, and Y. Horie, eds., AIP Press, 2002, p. 966.

[3] R. L. Druce, F. Roeske, P. C. Souers, C. M. Tarver, C. T. S. Chow, R. S. Lee, E. M. McGuire, G. E. Overturf, and P. A. Vitello, "Propagation of Axially Symmetric Detonation Waves," Twelfth International Detonation Symposium, San Diego, CA, August 2002, in press.

[4] Y. B. Zeldovich, J. Exper. Theor. Phys. (USSR) 1940, 10, 542.

[5] J. Von Neumann, Office of Science Research Development, Report No. 549, 1942.

[6] W. Doring, Am. Physik 1943, 43, p. 421.

[7] W. W. Wood and J. G. Kirkwood, J. Chem. Phys. 1958, 29, 957.

[8] E. L. Lee and C. M. Tarver, "Phenomenological Model of Shock Initiation in Heterogeneous Explosives," Phys. Fluids 1980, 23, 2362.

[9] B. Hayes and C. M. Tarver, "Interpolation of Detonation Parameters from Experimental Particle Velocity Records," Seventh Symposium (International) on Detonation, Annapolis, MD, 1981, p. 1029.

[10] C. M. Tarver and J. O. Hallquist, "Modeling Two Dimensional Shock Initiation and Detonation Wave Phenomena in PBX 9404 and LX-17," Seventh Symposium (International) on Detonation, Annapolis, MD, 1981, p. 488.

[11] C. M. Tarver, N. L. Parker, H. G. Palmer, B. Hayes, and L. M. Erickson, "Reactive Flow Modeling of Recent Embedded Gauge and Metal Acceleration Experiments on Detonating PBX 9404 and LX-17," J. Energetic Materials 1983, 1, 213.

[12] S. A. Sheffield, D. D. Bloomquist, and C. M. Tarver, "Subnanosecond Measurements of Detonation Fronts in Solid High Explosives," J. Chem. Phys. 1984, 80, 3831.

[13] L. Green, E. Lee, A. Mitchell, and C. Tarver, "The Supra-Compression of LX-07, LX-17, PBX-9404, and RX26-AF and the Equation of State of the Detonation Products," Eighth Symposium (International) on Detonation, Albuquerque, NM, 1985, p. 587. 
[14] C. M. Tarver, J. O. Hallquist, and L. M. Erickson, "Modeling Short Pulse Duration Shock Initiation of Solid Explosives," Eighth Symposium (International) on Detonation, Albuquerque, NM, 1985, p. 951.

[15] E. Lee, D. Breithaupt, C. McMillan, N. Parker, J. Kury, C. Tarver, W. Quirk, and J. Walton, "The Motion of Thin Metal Walls and the Equation of State of Detonation Products," Eighth Symposium (International) on Detonation, Albuquerque, NM, 1985, p. 613.

[16] K. Bahl, G. Bloom, L. Erickson, R. Lee, C. Tarver, W. Von Holle, and R. Weingart, "Initiation Studies on LX17 Explosive," Eighth Symposium (International) on Detonation, Albuquerque, NM, 1985, p. 1045.

[17] C. M. Tarver, R. D. Breithaupt, and J. W. Kury, "Current Experimental and Theoretical Understanding of Detonation Waves in Heterogeneous Solid Explosives," International Symposium on Pyrotechnics and Explosives, Beijing, China, 1987, p. 692.

[18] C. M. Tarver and D. E. Maiden, "Experimental Measurements and Numerical Simulations of Metal Spallation by Detonating Solid Explosives," Shock Waves in Condensed Matter-1987, Elsevier Science Publishers B. V., New York, 1988, p. 363.

[19] L. G. Green, C. M. Tarver, and D. J. Erskine, "Reaction Zone Structure in Supracompressed Detonating Explosives," Ninth Symposium (International) on Detonation, Portland, OR, 1989, p. 670.

[20] K. L. Bahl, R. D. Breithaupt, C. M. Tarver, and W. G. Von Holle, "Fabry-Perot Velocimetry on Detonating LX17 in Planar and Spherically Divergent Geometries," Ninth Symposium (International) on Detonation, Portland, OR, 1989, p. 133.

[21] C. M. Tarver, "Modeling Shock Initiation and Detonation Divergence Tests on TATB-Based Explosives," Propellants, Explosives, Pyrotechnics 1990, 15, 132.

[22] C. M. Tarver, W. C. Tao, and C. G. Lee, "Sideways Plate Push Test for Detonating Solid Explosives," Propellants, Explosives, Pyrotechnics 1996, 21, 238.

[23] C. M. Tarver, J. W. Kury, and R. D. Breithaupt, “Detonation Waves in Triaminotrinitrobenzene,” J. App. Phys. 1997, 82, 3771 .

[24] C. M. Tarver, R. D. Breithaupt and J. W. Kury, "Detonation Waves in Pentaerythritol Tetranitrate," J. App. Phys. 1997, 81, 7193.

[25] J. W. Kury, R. D. Breithaupt, and C. M. Tarver, "Detonation Waves in Trinitrotoluene," Shock Waves 1999, 9 , 227. 
[26] C. M. Tarver and E. M. McGuire, "Reactive Flow Modeling of the Interaction of TATB Detonation Waves with Inert Materials," Twelfth International Detonation Symposium, San Diego, CA, August 2002, in press.

[27] T. D. Tran, C. M. Tarver, J. Maienschein, P. Lewis, M. Moss, R. S. Lee, and F. Roeske, "Characterization of Detonation WAVE Propagation in LX-17 near the Critical Diameter," Twelfth International Detonation Symposium, San Diego, CA, August 2002, in press.

[28] F. Roeske, Lawrence Livermore National Laboratory, private communication, 2003.

[29] J. D. Molitoris, Lawrence Livermore National Laboratory, private communication, 2003.

[30] R. G. Whirley, B. E. Englemann, and J. O. Hallquist, "DYNA2D User Manual,” Lawrence Livermore National Laboratory Report UCRL-MA-110630, 1992.

[31] C. M. Tarver, "Multiple Roles of Highly Vibrationally Excited Molecules in the Reaction Zones of Detonation Waves," J. Phys. Chem. A, 1997, 101, 4845.

[32] A. L. Nichols III and C. M. Tarver, "A Statistical Hot Spot Reactive Flow Model for Shock Initiation and Detonation of Solid High Explosives," Twelfth International Detonation Symposium, San Diego, CA, August 2002, in press. 
Table 1. Ignition and Growth Parameters for LX-17 and Ultrafine TATB
A. $25^{\circ} \mathrm{C}$ LX-17
$\rho_{\mathrm{o}}=1.905 \mathrm{~g} / \mathrm{cm}^{3}$
UNREACTED JWL
PRODUCT JWL
REACTION RATES
$\mathrm{A}=778.1 \mathrm{Mbar}$
$\mathrm{B}=-0.05031 \mathrm{Mbar}$
$\mathrm{A}=14.8105 \mathrm{Mbar}$
$\mathrm{I}=4.0 \times 10^{6} \mu_{\mathrm{s}}-1$
$\mathrm{R}_{1}=11.3$
$\mathrm{B}=0.6379 \mathrm{Mbar}$
$\mathrm{a}=0.22$
$\mathrm{R}_{2}=1.13$
$\mathrm{R}_{1}=6.2$
$\mathrm{b}=0.667$
$\mathrm{R}_{2}=2.2$
$\mathrm{x}=7.0$
$\mathrm{F}_{\text {igmax }}=0.02$
$\omega=0.8938$
$\omega=0.5$
$\mathrm{C}_{\mathrm{V}}=2.487 \times 10^{-5} \mathrm{Mbar} / \mathrm{K}$
$\mathrm{C}_{\mathrm{V}}=1.0 \times 10^{-5} \mathrm{Mbar} / \mathrm{K}$
$\mathrm{G}_{1}=4600 \mathrm{Mbar}^{-3} \mu \mathrm{s}^{-1}$
$\mathrm{T}_{\mathrm{O}}=298^{\circ} \mathrm{K}$
$\mathrm{E}_{\mathrm{O}}=0.069 \mathrm{Mbar}$
$\mathrm{c}=0.667$
Shear Modulus $=0.0354 \mathrm{Mbar}$
$\mathrm{d}=1.0$
$\mathrm{y}=3.0 \quad \mathrm{~F}_{\mathrm{G}_{1} \max }=0.8$
Yield Strength $=0.002 \mathrm{Mbar}$
$\mathrm{G}_{2}=30 \mathrm{Mbar}^{-1} \mu \mathrm{s}^{-1}$
$\mathrm{e}=0.667$
$\mathrm{g}=0.667$
$\mathrm{z}=1.0$
$\mathrm{FG}_{2}$ min $=0.8$

Calculated Failure Diameter $=>12 \mathrm{~mm}$ and $<13 \mathrm{~mm}$

Other Reaction Growth Parameter Sets $\quad \mathrm{y}=2$ and $\mathrm{G}_{1}=1100 ; \mathrm{y}=4$ and $\mathrm{G}_{1}=23000$

B. $25^{\circ} \mathrm{C}$ Ultrafine TATB

$\rho_{\mathrm{o}}=1.80 \mathrm{~g} / \mathrm{cm}^{3}$

UNREACTED JWL

\section{PRODUCT JWL}

$\mathrm{A}=632.07 \mathrm{Mbar}$

$\mathrm{B}=-0.04472 \mathrm{Mbar}$

$\mathrm{R}_{1}=11.3$

$\mathrm{R}_{2}=1.13$

$\omega=0.8938$

$\mathrm{C}_{\mathrm{V}}=2.487 \times 10^{-5} \mathrm{Mbar} / \mathrm{K}$

$\mathrm{T}_{\mathrm{O}}=298^{\circ} \mathrm{K}$

Shear Modulus $=0.030 \mathrm{Mbar}$

Yield Strength $=0.002 \mathrm{Mbar}$

$$
\begin{aligned}
& A=12.05026 \mathrm{Mbar} \\
& B=0.602513 \mathrm{Mbar} \\
& \mathrm{R}_{1}=6.2 \\
& \mathrm{R}_{2}=2.2 \\
& \omega=0.5 \\
& \mathrm{C}_{\mathrm{V}}=1.0 \times 10^{-5} \mathrm{Mbar} / \mathrm{K} \\
& \mathrm{E}_{\mathrm{O}}=0.069 \mathrm{Mbar}
\end{aligned}
$$

\section{REACTION RATES}

$$
\mathrm{I}=4.0 \times 10^{6} \mu \mathrm{s}^{-1}
$$$$
\mathrm{a}=0.22
$$

$\mathrm{b}=0.667$

$\mathrm{x}=7.0$

$\mathrm{F}_{\text {igmax }}=0.071$

$\mathrm{G}_{1}=2200 \mathrm{Mbar}^{-2} \mu \mathrm{s}^{-1}$

$\mathrm{c}=0.667$

$\mathrm{d}=1.0$

$\mathrm{y}=2.0 \quad \mathrm{~F}_{\mathrm{G}_{1} \max }=1.0$

$\mathrm{G}_{2}=60 \mathrm{Mbar}^{-1} \mu \mathrm{s}^{-1}$

$\mathrm{e}=0.667 \quad \mathrm{z}=1.0$

$\mathrm{g}=0.667 \quad \mathrm{FG}_{2} \min =0.8$

C. C-J Detonation Parameters for PBX 9407
$\rho_{\mathrm{o}}=1.60 \mathrm{~g} / \mathrm{cm} 3$
$\mathrm{D}=0.791 \mathrm{~cm} / \mu \mathrm{s}$
$\mathrm{P}_{\mathrm{C}-\mathrm{J}}=0.265 \mathrm{Mbar}$
$\mathrm{Eo}=0.086 \mathrm{Mbar}$
$\mathrm{A}=5.73187 \mathrm{Mbar}$
$\mathrm{B}=0.14639 \mathrm{Mbar}$
$\mathrm{R}_{1}=4.6$
$\mathrm{R}_{2}=1.4$
$\omega=0.32$ 


\section{FIGURE CAPTIONS}

Figure 1. Experimental geometry for the $25.4 \mathrm{~mm}$ wide LX-17 hockey puck

Figure 2. Experimental breakout times along the LX-17 perimeters for the $12.7 \mathrm{~mm}$ and $25.4 \mathrm{~mm}$ wide hockey pucks

Figure 3. Experimental and calculated breakout times along the LX-17 perimeter for the $12.7 \mathrm{~mm}$ wide hockey puck

Figure 4. Experimental and calculated breakout times along the LX-17 perimeter for the $25.4 \mathrm{~mm}$ wide hockey puck

Figure 5. Fraction reacted contours for the $25.4 \mathrm{~mm}$ wide hockey puck5.5 $\mu$ s after initiation $(2.735 \mu \mathrm{s}$ after booster breakout)

Figure 6. Fraction reacted contours for the $25.4 \mathrm{~mm}$ wide hockey puck6 $\mu$ s after initiation $(3.235 \mu \mathrm{s}$ after booster breakout)

Figure 7. Fraction reacted contours for the $25.4 \mathrm{~mm}$ wide hockey puck6.5 $\mu$ s after initiation $(3.735 \mu$ s after booster breakout)

Figure 8. Calculated breakout times using pressure squared, pressure cubed, and pressure quadrupled reaction rates for $12.7 \mathrm{~mm}$ wide LX-17

Figure 9. Calculated breakout times using pressure squared, pressure cubed, and pressure quadrupled reaction rates for $25.4 \mathrm{~mm}$ wide LX-17 


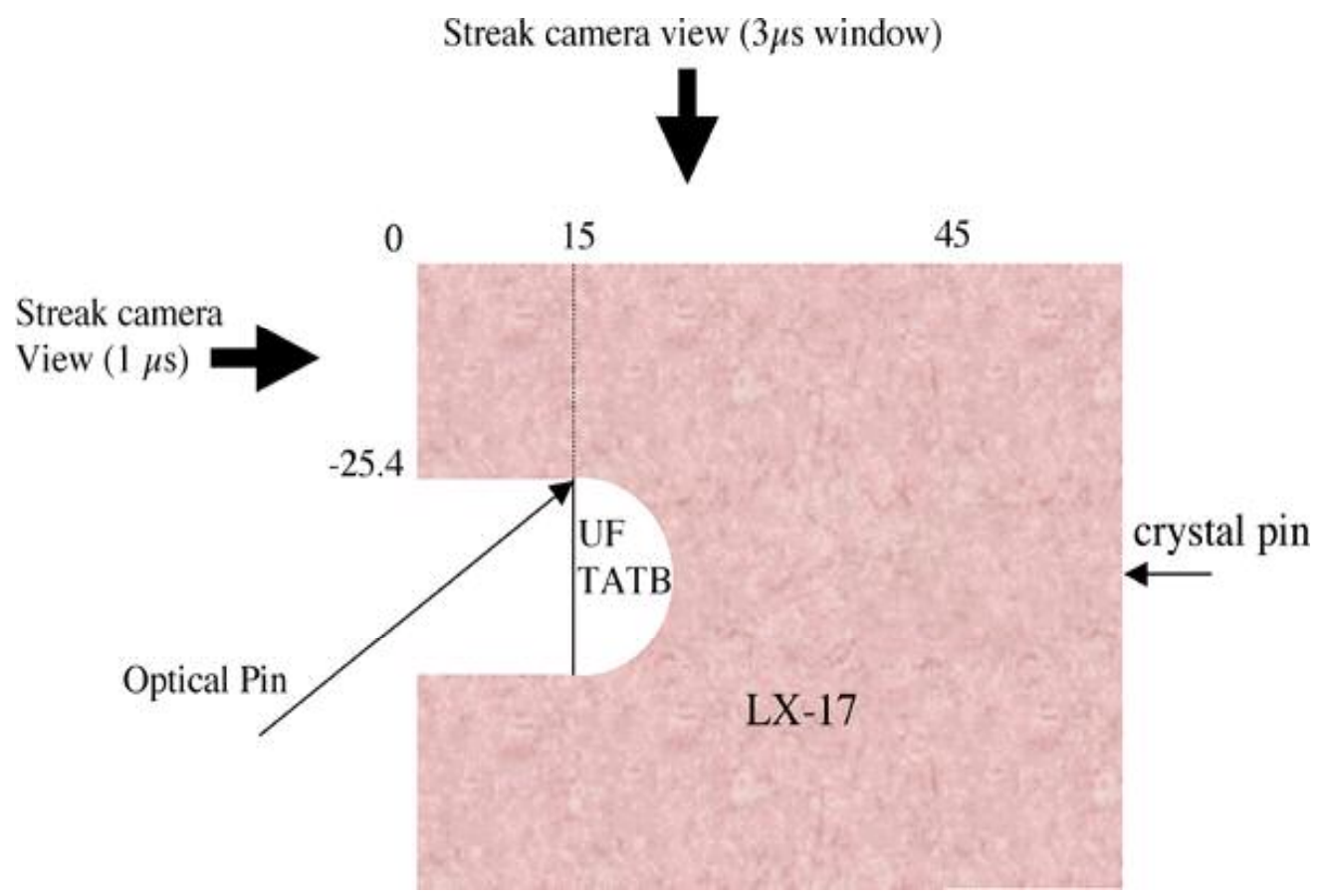

Figure 1. Experimental geometry for the $25.4 \mathrm{~mm}$ wide LX-17 hockey puck 




Figure 2. Experimental breakout times along the LX-17 perimeters for the $12.7 \mathrm{~mm}$ and $25.4 \mathrm{~mm}$ wide hockey pucks 


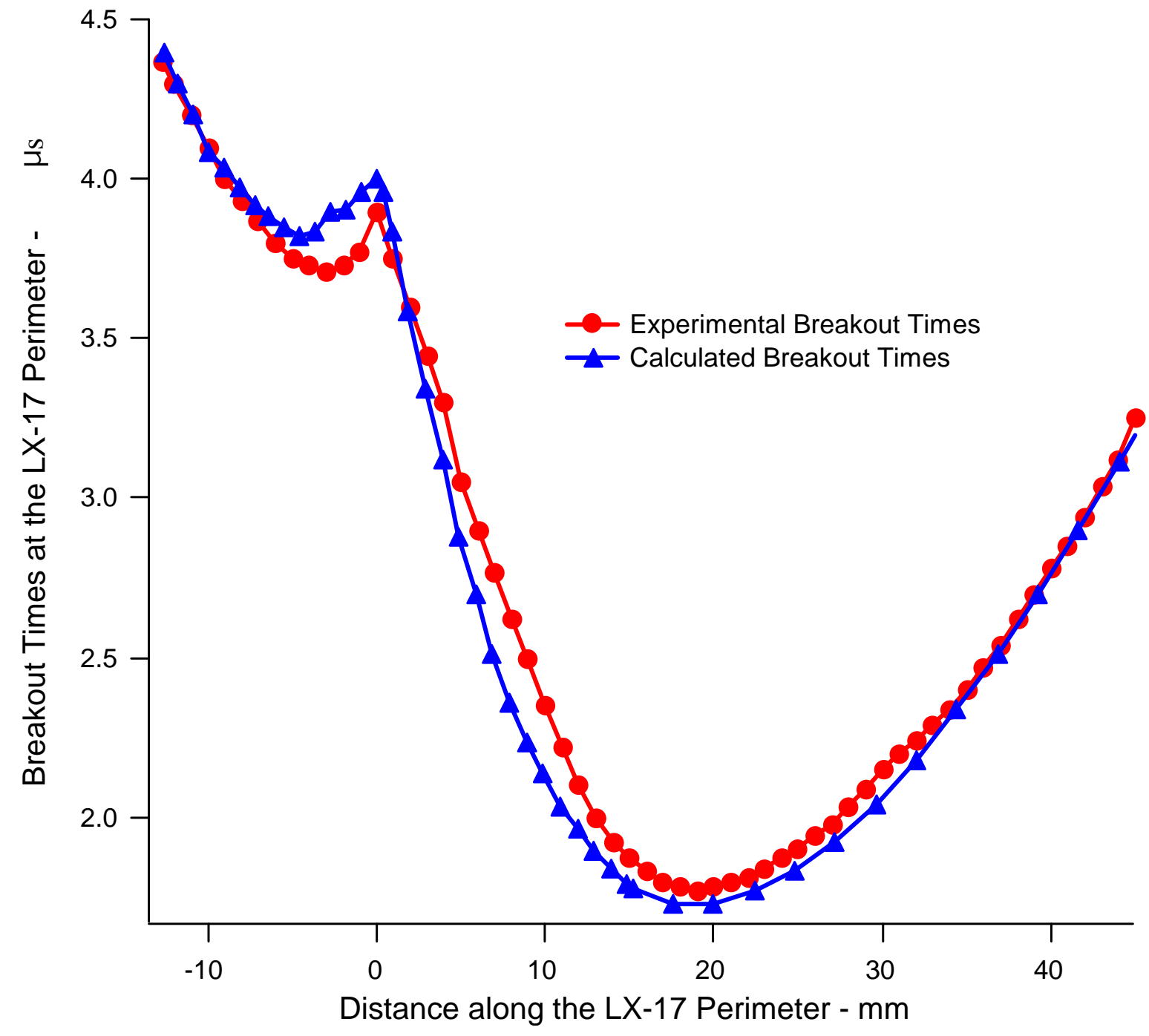

Figure 3. Experimental and calculated breakout times along the LX-17 perimeter for the $12.7 \mathrm{~mm}$ wide hockey puck 


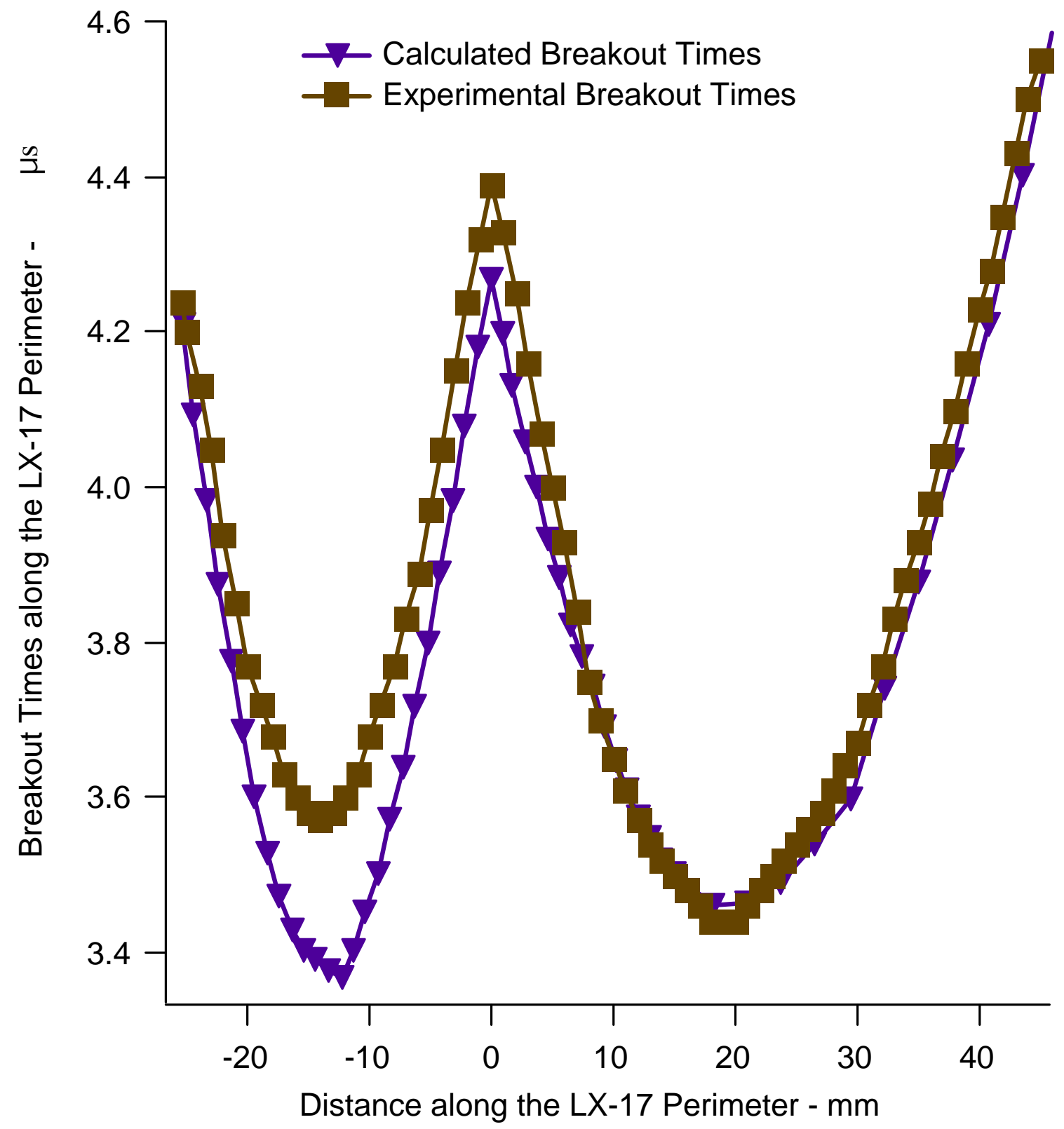

Figure 4. Experimental and calculated breakout times along the LX-17 perimeter for the $25.4 \mathrm{~mm}$ wide hockey puck 
QuickTime ${ }^{\mathrm{TM}}$ and a
Photo - JPEG decompressor are needed to see this picture.

Figure 5. Fraction reacted contours for the $25.4 \mathrm{~mm}$ wide LX-17 hockey puck $5.5 \mu$ s after initiation $(2.735 \mu$ s after booster breakout) 
QuickTime ${ }^{\mathrm{TM}}$ and a

are no - JPEG decompressor

Figure 6. Fraction reaction contours for the $25.4 \mathrm{~mm}$ wide LX-17 hockey puck $6 \mu$ s after initiation ( $3.235 \mu$ s after booster breakout) 
QuickTime ${ }^{\mathrm{TM}}$ and a

are needed to see this picture.

Figure 7. Fraction reacted contours for the $25.4 \mathrm{~mm}$ wide LX-17 hockey puck $6.5 \mu$ s after initiation (3.735 $\mu$ s after booster breakout) 


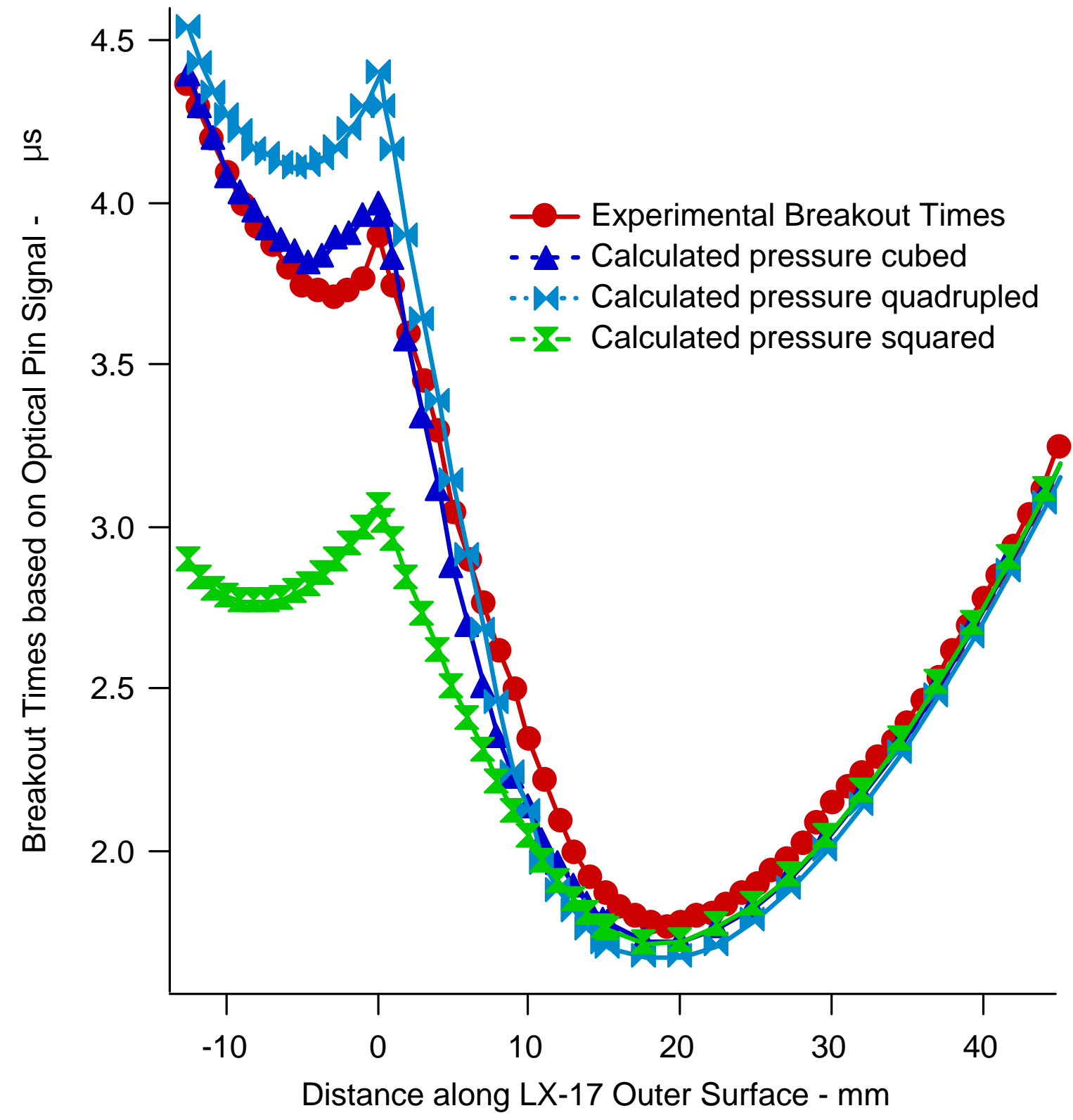

Figure 8. Calculated breakout times using pressure squared, pressure cubed, and pressure quadrupled reaction rates for $12.7 \mathrm{~mm}$ wide LX-17 


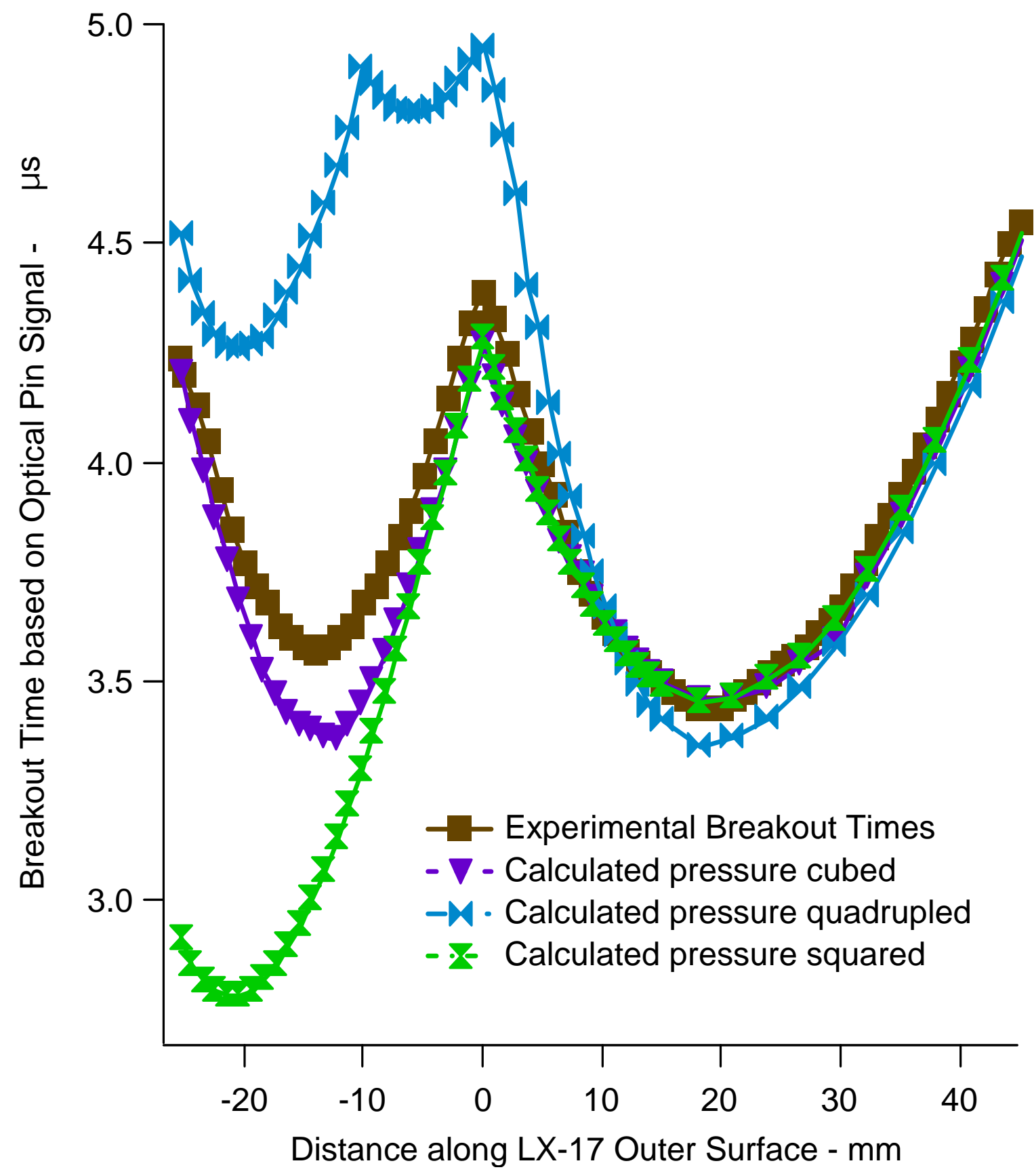

Figure 9. Calculated breakout times using pressure squared, pressure cubed, and pressure quadrupled reaction rates for $25.4 \mathrm{~mm}$ wide LX-17 